\title{
STUDI WAKTU PELAYANAN KAPAL DI DERMAGA I PELABUHAN BAKAUHENI
}

\author{
Galuh Pramita ${ }^{1}$, Arlina Phelia ${ }^{2}$, Nurwanda Sari ${ }^{3}$ \\ Teknik Sipil Universitas Teknokrat Indonesia ${ }^{1}$ \\ Teknik Sipil Universitas Teknokrat Indonesia ${ }^{2}$ \\ Institut Teknologi Sumatera ${ }^{3}$ \\ galuh.pramita@teknokrat.ac.id
}

\begin{abstract}
Received: (5 Juni 2020)
Accepted: (30 Juni 2020)

Published : (30 Juli 2020)

Abstract

Bakauheni Port, located in Lampung Province, is the ferry ports serving ships from Sumatra Island heading to Java Island or vice versa. In general case, the problem of service performance often encounteres in port operations. Ineffective management of the port is one of the obstacles in service. The queue system of waiting ships during docking activity is one of the result of ineffective management of the ports operations. The purpose of this study was to calculate the time taken by ship in maneuvering, raise and drop off passengers at the Pier I of the Bakauheni Port. The research was conducted by surveys at dock I of the Bakauheni Port during the normal condition. Data were analysed so as to know the operational time required for loading and unloading ships and maneuver. Based on data analysis, it can be concluded that the headway value of each ship operating at Pier I is: Suki 59,50 minutes, BSP I 56,45 minutes, Mustika Kencana 50,13 minutes, HM Baruna 53,64 minutes, Jatra 2 45,91 minutes, 45,91 minutes and Shalem 44,97 minutes. The average headway of the ships at Pier I was 51,77 minutes. From the value, it shows the operating in Pier I Bakauheni Port has already reached optimum due to total time needed less than the time determined by Bakauheni Port with a total 24 ship trip in Pier I.
\end{abstract}

Keywords: Port, Headway Pier, Manuevering Time, Loading dang Unloading Time

\begin{abstract}
Abstrak
Pelabuhan Bakauheni yang terletak di Provinsi Lampung adalah pelabuhan yang melayani penyebrangan dari Pulau Sumatera ke Pulau Jawa atau sebaliknya. Permasalahan kinerja pelayanan sering dijumpai dalam operasional pelabuhan. Pengelolaan pelabuhan yang belum efektif merupakan salah satu kendala dalam pelayanan. Terjadinya antrian kapal karena harus menunggu kapal yang belum selesai melakukan bongkar muat didermaga merupakan salah satu akibat tidak optimalnya pelayanan pelabuhan. Penelitian ini dilakukan untuk menghitung waktu pelayanan kapal yaitu berupa waktu dibutuhkan oleh kapal untuk melakukan manuver, menaikan dan menurunkan penumpang didermaga I Pelabuhan Bakauheni. Penelitian ini dilaksanakan dengan melaksanaka survey di Dermaga I Pelabuhan Bakauheni pada waktu kondisi arus normal. Pendekatan yang dilakukan untuk mencapai hasil adalah dengan melakukan analisis data menentukan lama waktu sandar dan lama waktu manuver kapal. Berdasarkan analisis data dapat disimpulkan bahwa nilai headway masing - masing kapal yang beroperasi didermaga I yaitu : Suki sebesar 59,50 menit, BSP I sebesar 56,45 menit, Mustika Kencana sebesar 50,13 menit, HM Baruna sebesar 53,64 menit, Jatra 2 sebesar 45,91 menit dan Shalem sebesar 44,97 menit. Rata - rata headway kapal didermaga I adalah 51,77 menit. Dari nilai tersebut menunjukkan bahwa operasional kapal di Dermaga I Pelabuhan Bakauheni sudah optimal karena kurang dari waktu yang telah ditetapkan oleh Pelabuhan Bakauhen dengan total 24 trip kapal di Dermaga I.
\end{abstract}

Kata Kunci: Pelabuhan, Headway, Dermaga, Waktu Manuver, Waktu Bongkar Muat

To cite this article: Pramita (2020). Studi Waktu Pelayanan Kapal Di Dermaga I Pelabuhan Bakauheni. Journal of Infrastructural in Civil Engineering (JICE), Vol(1), 19-29.

\section{PENDAHULUAN}

Provinsi Lampung memiliki Pelabuhan Bakauheni yang melayani penyebrangan di Pulau Seumatera menuju Pulau Jawa. Sebagai Pelabuhan yang terletak di ujung Pulau Sumatera, Pelabuhan Bakauheni berkembang 
untuk terwujudnya pelabuhan penyeberangan yang dapat melayani kebutuhan masyarakat. Pelabuhan Bakauheni - Merak dipisahkan oleh Selat Sunda yang mempunyai jarak 16 mil $(25.75 \mathrm{~km})$ dapat ditempuh dengan 120 menit. Dermaga yang dimiliki Pelabuhan Bakauheni adalah tipe moveable bridge yang digunakan untuk aktivitas bongka muat kendaraan dan penumpang.

Pelabuhan merupakan simpul antara transportasi darat dengan transportasi laut (Warpani, 1990). PT. ASDP Cabang Utama Bakauheni berusaha memenuhi kebutuhan masyarakat di pulau Sumatera dan sekitarnya akan fasilitas sosial berupa fasilitas penyeberangan, perpakiran, keamanan, transportasi dan kenyamanan. Untuk mewujudkan transportasi yang efektif dan efisien, pihak pelabuhan harus dapat memadukan kepentingan pengguna jasa dan penyedia jasa. Hal itu dapat dilakukan dengan memanfaatkan sepenuhnya ruang kapal, meminimalisir waktu tempuh dan mengoptimalkan waktu sandar.

Permasalahan pelayanan operasional sering terjadi di kawasan pelabuhan. Pengelolaan pelabuhan yang belum efektif merupakan salah satu kendala dalam operasional pelayanan pelabuhan. Antrian kapal sering terjadi di pelabuhan karena harus menunggu kapal yang sedang bersandar di dermaga melakukan bongkar muat, hal dapat mengakibatkan tidak optimalnya pelayanan pelabuhan. Salah satu hal yang dilakukan untuk meningkatkan pelayanan adalah dengan mempercepat waktu berlayar (sailing time) dan meminimalkan waktu bongkar muat (port time).

Tujuan penelitian ini adalah untuk menghitung waktu pelayanan kapal yaitu berupa waktu dibutuhkan oleh kapal untuk melakukan manuver, menaikan dan menurunkan penumpang didermaga I Pelabuhan Bakauheni. Penelitian ini dapat dijadikan acuan dalam pengaturan jadwal angkutan penyeberangan. Penelitian ini dilaksanakan pada waktu kondisi arus normal.

\section{DAFTAR PUSTAKA \\ Pelabuhan Bakauheni dan Merak}

Pelabuhan Penyeberangan Bakauheni adalah pelabuhan yang terletak di Provinsi Lampung. Pelabuhan Bakauheni menghubungkan Pulau Sumatera dan Pulau Jawa melalui via laut. Luas pelabuhan Penyeberangan Bakauheni adalah $452.458 \mathrm{~m}^{2}$ (Badan Penelitian dan Pengembangan Perhubungan Kementrian Perhubungan, November 2010).

Pelabuhan penyeberangan Merak yang terletak di Provinsi Banten adalah pelabuhan umum yang melayani penyeberangan antara Pulau Jawa dan Sumatera (Andriani, 2011). Luas Pelabuhan Penyeberangan Merak adalah150.615 $\mathrm{m}^{2}$. Pelabuhan Penyeberangan Merak dan Pelabuhan Bakauheni memiliki 1 dermaga executive 6 dan dermaga regular.

Kapal feri ro-ro adalah kapal yang melayani Penyeberangan Bakauheni - Merak. Pelabuhan Bakauheni melayani arus penumpang dan kendaraan dari dan ke Pulau Sumatra. Rata-rata durasi yang dibutuhkan untuk kapal berlayar dari Pelabuhan Bakauheni atau Pelabuhan Merak sekitar 120 menit.

\section{Fasilitas Pelabuhan}

Dermaga

Dermaga adalah bangunan dipelabuhan yang digunakan kapal bersandar dan melakukan menaik-turunkan penumpang dan bongkar muat barang (Triatmojo, 1996). Ukuran dermaga bergantung dari jenis dan ukuran kapal yang akan bersandar pada dermaga tersebut (Solossa, 2013). Tipe dermaga yang dimiliki Pelabuhan Penyeberangan Bakauheni adalah tipe Qual Wall, Dolphin dan Jetty. Pelabuhan Penyeberangan Bakuheni pada saat ini memiliki tujuh dermaga dengan satu dermaga executive yang digunakan untuk bongkar muat barang dan menaik-turunkan penumpang.

Kapal yang beroperasi

Pelabuhan Penyeberangan Bakauheni dan Pelabuhan Merak menggunakan kapal jenis Ro-Ro (Roll on Roll off) untuk menyebrangkan kendaraan dan penumpang. Kapal Ro-Ro (Roll on - Roll off) adalah kapal yang bisa memuat kendaraan yang berjalan masuk ke dalam kapal. Kapal ini dilengkapi dengan pintu rampa yang dihubungkan dengan moveble bridge atau dermaga apung ke dermaga. Kapal Ro-Ro selain digunakan untuk angkutan truk juga digunakan untuk mengangkut mobil penumpang, sepeda motor dan pejalan kaki.

Pelabuhan Penyeberangan Bakauheni memiliki 57 kapal yang tersedia untuk melayani penumpang yang akan menyeberang ke Pulau Jawa. Setiap harinya Pelabuhan Bakauheni mengoperasikan sekitar 24 kapal. Kapal - kapal yang beroperasi di lintasan Bakauheni - Merak telah memiliki jadwal operasi dan formasi kapal yang bersandar pada masing-masing dermaga yang ada di Pelabuhan Bakauheni. 


\section{Sistem Angkutan Penyeberangan dan Rencana Operasi}

Sistem Angkutan Penyeberangan

Sistem angkutan penyeberangan meliputi alur pelayaran, ukuran dan tipe kapal, jadwal waktu pelayaran, dan dampak lingkungan.

Alur Penyeberangan

Untuk menentukan alur pelayaran perlu ditinjau terlebih dahulu kondisi perairannya, orientasi permintaan, penyebaran permintaan, jarak dan waktu tempuh.

Ukuran dan tipe kapal

Ukuran dan tipe kapal ditentukan berdasarkan pendekatan dua besaran. Pertama, berdasarkan tuntutan keamanan dan keselamatan dalam pelayaran yang merupakan fungsi dari kondisi perairan sepanjang alur pelayaran.Sedangkan, tipe kapal ditentukan dari kebutuhan permitaan (penumpang dan barang) yang akan dilayani.

Jadwal dan pelayaran

Untuk menentukan jadwal pelayaran didasarkan pola distribusi waktu dan justifikasi konsultan. Justifikasi ini berdasarkan pada kebutuhan pokok, serta kegiatan bahari. Dari sisi bahan pokok, maka dengan kondisi geografis yang dibatasi oleh perairan, harus dapat dijamin ketersediaan bahan pokok tersebut setiap waktunya. Dengan demikian, dari pendekatan kapasitas penumpukan dan pendistribusian dapat diketahui jadwal pengirimannya.

Dampak lingkungan

Dampak lingkungan yang umumnya terjadi pada pengembangan pelabuhan adalah dampak sosial, pada umumnya adalah dampak sosial, pada saat proses pembebasan tanah, dan karena terjadinya perubahan fungsi kawasan.

\section{Rencana Pola Operasi}

Pola operasi adalah menentukan jumlah kapal yang beroperasi dan frekuensi yang diperlukan kapal tersebut dalam tiap lintasan sesuai dengan jenis kapal yang beroperasi dan jarak lintasan.

Waktu siklus kapal dapat dihitung dengan menggunakan rumus (1), dapat dilihat sebagai berikut

$$
\begin{aligned}
& \mathrm{Tc} \quad=2(\mathrm{Ts}+\mathrm{Tm}+\mathrm{Tp}) \\
& \mathrm{Dimana}: \\
& \mathrm{Tc} \quad=\text { waktu siklus }(\text { cycle time }) \\
& \mathrm{Tp} \quad=\text { waktu bersandar ( port time }) \\
& \mathrm{Tm} \quad=\text { waktu manuver kapal (manuver time) } \\
& \mathrm{Ts} \quad=\text { waktu berlayar (sailing time) }
\end{aligned}
$$

Adapun untuk menghitung waktu bersandar kapal (port time) atau Tp dapat menggunakan rumus (2) perhitungan sebagai berikut :

$$
\mathrm{Tp}=\mathrm{tb}+\mathrm{tm}
$$

Dimana

Tp = waktu bersandar kapal yang terdiri dari waktu bongkar muat (tm) kendaraan dalam satuan menit.

tb = rata-rata waktu menurunkan kendaraan (menit/kendaraan)

$\mathrm{tm}=$ rata-rata waktu menaikkan kendaraan (menit/kendaraan)

Waktu manuver kapal dapat dihitung dengan menggunakan rumus (3) berikut :

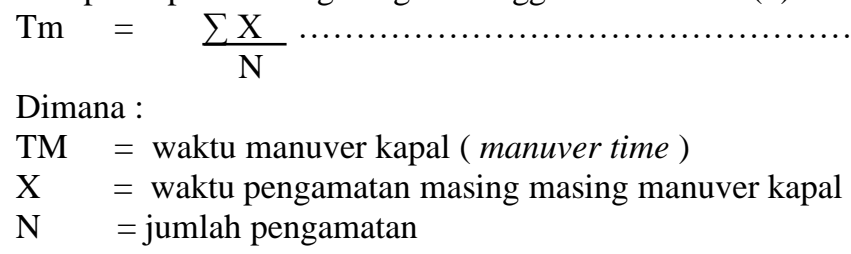

Waktu rata-rata menaikkan kendaraan digunakan rumus 4 sebagai berikut :

$$
\mathrm{tm}=\frac{\sum \mathrm{tm}}{\mathrm{N}}
$$

Dimana :

$\mathrm{Tm} \quad$ = rata-rata waktu menaikkan kendaraan

$\sum \mathrm{tm}=$ total waktu menaikkan kendaraan dari masing-masing kapal 
$\mathrm{N}=$ jumlah kendaraan

Waktu rata-rata menurunkan kendaraan dapat menggunakan rumusan 5 berikut :

$\mathrm{tb}=\frac{\sum \mathrm{tb}}{\mathrm{N}}$

$\mathrm{tb} \quad=$ rata-rata waktu menurunkan kendaraan

$\sum$ tb $=$ total waktu menurunkan kendaraan dari masing-masing kapal

$\mathrm{N} \quad=$ jumlah kendaraan

Untuk menghitung headway masing-masing kapal dapat menggunakan persamaan 6 berikut :
$\mathrm{Hw}=\mathrm{tb}+\mathrm{tm}+\mathrm{TP}$
Dimana :
$\mathrm{Hw} \quad=$ headway keberangkatan kapal
$\mathrm{tb} \quad=$ rata - rata waktu menurunkan kendaraan
$\mathrm{tm} \quad=$ rata-rata waktu menaikkan kendaraan
$\mathrm{TP} \quad=$ waktu bersandar (berlabuh) kapal

Untuk menentukan frekuensi pelayaran yang dibutuhkan yaitu berdasarkan permintaan penumpang dan barang. Untuk kepentingan perencanaan digunakan frekuensi pelayanan yang terbesar di antara dua metode. Metode perhitungan yang digunakan adalah sebagai berikut:

a. Berdasarkan jumlah permintaan barang

b. Berdasarkan Sistem Penyediaan Dermaga

\section{METODE PENELITIAN}

\section{Data}

Data yang akan digunakan penelitian ini ada dua yaitu data primer dan data sekunder.

Data primer

Data primer adalah data yang diperoleh secara langsung melalui pengamatan langsung. Pada penelitian ini data yang diamati adalah data waktu pelayanan didermaga. Data yang diperoleh waktu bongkar muat kendaraan dan waktu manuver kapal.

Data Sekunder

Data sekunder merupakan data yang dari instansi terkait. Data yang dibutuhkan adalah :

- Data jumlah kapal yang tersedia dan beroperasi

- Data kapasitas kapal.

- Data jadwal keberangkatan kapal

- Data layout pelabuhan

\section{Pengumpulan Data}

Pengumpulan data dilakukan di Pelabuhan Bakauheni. Untuk mendapatkan data primer penulis melakukan pengamatan di Pelabuhan Bakauheni yaitu berupa waktu pelayanan kapal. Data sekunder didapatkan dari PT. ASDP Indonesia Ferry Cabang Bakauheni berupa data jumlah data jumlah kapal yang tersedia dan beroperasi, data kapasitas masing-masing dermaga dan kapal, data jadwal keberangkatan, dan data layout pelabuhan.

\section{Metode Analisis}

Pendekatan yang dilakukan untuk mencapai hasil adalah dengan melakukan analisis data menentukan lama waktu sandar dan lama waktu manuver kapal. Waktu sandar adalah waktu menaikkan dan menurunkan kendaraan. Headway (waktu antar kedatangan) terpendek kapal yang akan menggunakan dermaga di Pelabuhan. Waktu bongkar muat, waktu manuver, jumlah kapal yang tersedia mempengaruhi selang waktu keberangkatan kapal. 


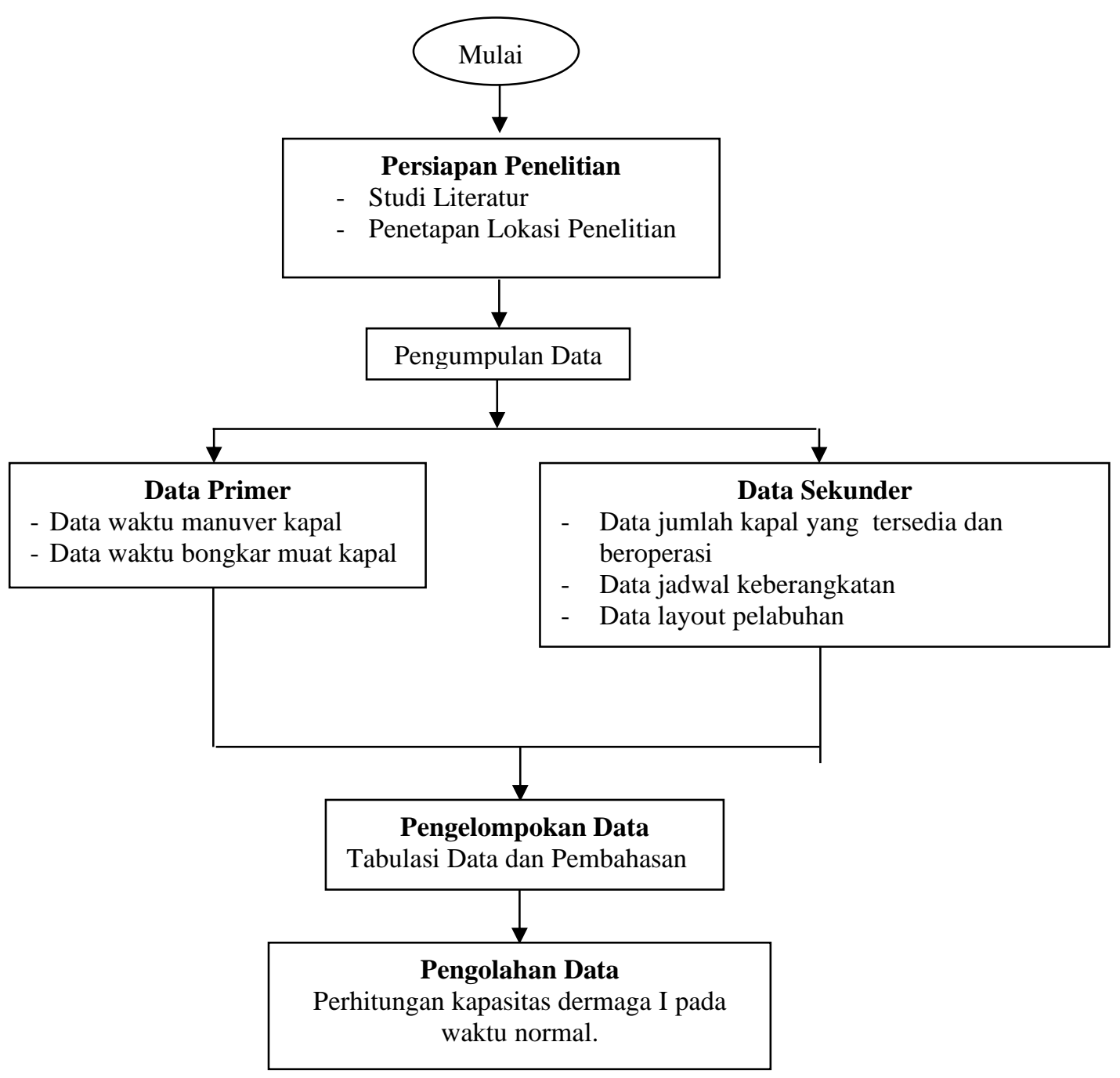

\section{HASIL DAN PEMBAHASAN}

Proses pelayanan kapak didermaga terdiri dari waktu maneuver kapal dan waktu bongkar muat kendaraan. Prosedur yang dilakukan untuk menurunkan kendaraan dimulai kerika ramp door terbuka dengan sempurna dan menyentuh moveable bridge (Karyawan, 2012). Sedangkan, unuk menaikkan kendaraan dimulai pada saat semua kendaraan didalam kapal telah turun dan anak buah kapal yang berada di dek kapal menyatakan siap untuk proses menaikkan kendaraan. Analisis waktu pelayanan dermaga dengan mendapatkan waktu rata-rata bongkar muat kendaraan roda empat naik dan turunnya kendaraan dari kapal serta waktu manuver kapal dapat dilihat sebagai berikut :

\section{Waktu Menurunkan kendaraan}

Untuk mendapatkan waktu menurunkan kendaraan, peneliti melakukan pengamatan. Total waktu yang didapat dari hasil pengamatan tersebut, untuk menurunkan 128 kendaraan dibutuhkan waktu selama 13 menit. Berikut perhitungan waktu menurunkan setiap unit kendaraan.

$$
\begin{aligned}
\mathrm{tb} \quad & \frac{\sum \mathrm{tb}}{\mathrm{N}} \\
& =\frac{13}{128} \\
& =0.1016 \text { menit/kendaraan }
\end{aligned}
$$

(lihat persamaan 5 )

Dengan nilai rata-rata 0.1016 menit diperoleh waktu menurunkan kendaraan dari masing masing kapal berdasarkan kapasitasnya dapat dilihat pada tabel berikut. 
Tabel 1. Waktu Menurunkan Kendaraan pada Setiap Kapal.

\begin{tabular}{ccccc}
\hline No & $\begin{array}{c}\text { Jenis Kapal yang } \\
\text { beroperasi }\end{array}$ & $\begin{array}{c}\text { Kapasitas } \\
\text { angkut Kend. } \\
\geq \text { roda empat }\end{array}$ & $\begin{array}{c}\text { Rata-rata } \\
\text { waktu } \\
\text { menurunkan } \\
\text { (menit) }\end{array}$ & $\begin{array}{c}\text { Waktu } \\
\text { menurunkan } \\
\text { Kendaraan } \\
\text { ( menit) }\end{array}$ \\
\hline 1 & Suki & 128 & 0.1016 & 13,00 \\
2 & BSP 1 & 115 & 0,1016 & 11,68 \\
3 & Mustika Kencana & 88 & 0,1016 & 8,94 \\
4 & HM Baruna & 103 & 0,1016 & 10,46 \\
5 & Jatra 2 & 70 & 0,1016 & 7,11 \\
6 & Shalem & 66 & 0,1016 & 6,70 \\
\hline
\end{tabular}

\section{Waktu Menaikkan Kendaraan}

Untuk mendapatkan waktu menurunkan kendaraan, peneliti melakukan pengamatan. Total waktu yang didapat dari hasil pengamatan untuk menaikkan 128 kendaraan dibutuhkan waktu selama 17 menit. Untuk menghitung rata - rata kendaraan yang dimuat digunakan persamaan. Waktu menurunkan setiap unit kendaraan sebesar :

$$
\begin{aligned}
\mathrm{tm} & =\frac{\sum \mathrm{tm}}{\mathrm{N}} \quad \text { (lihat persamaan } 4 \text { ) } \\
\mathrm{tm} & =\frac{17}{128} \\
\mathrm{tm} & =0,1328 \text { menit/kendaraan }
\end{aligned}
$$

Dengan nilai rata-rata 0,1328 menit didapatkan waktu menurunkan kendaraan pada setiap kapal berdasarkan kapasitasnya dapat dilihat pada tabel berikut.

Tabel 2. Waktu Menaikkan Kendaraan pada masing- masing Kapal.

\begin{tabular}{ccccc}
\hline No & $\begin{array}{c}\text { Jenis Kapal yang } \\
\text { beroperasi }\end{array}$ & $\begin{array}{c}\text { Kapasitas } \\
\text { angkut Kend. } \\
\geq \text { roda empat }\end{array}$ & $\begin{array}{c}\text { Rata-rata waktu } \\
\text { menaikkan } \\
\text { (menit) }\end{array}$ & $\begin{array}{c}\text { Waktu } \\
\text { menaikkan } \\
\text { Kendaraan } \\
\text { ( menit) }\end{array}$ \\
\hline 1 & Suki & 128 & 0,1328 & 17,00 \\
2 & BSP 1 & 115 & 0,1328 & 15,27 \\
3 & Mustika Kencana & 88 & 0,1328 & 11,69 \\
4 & HM Baruna & 103 & 0,1328 & 13,68 \\
5 & Jatra 2 & 70 & 0,1328 & 9,30 \\
6 & Shalem & 66 & 0,1328 & 8,77 \\
\hline
\end{tabular}

\section{Waktu Manuver Kapal}

Waktu manuver kapal adalah waktu oleh gerak masuk dan keluar kapal dari area pelabuhan. Waktu olah gerak masuk kapal adalah waktu yang diperlukan kapal saat sampai dipelabuhan untuk bersandar sampai kapal tersebut siap melakukan bongkar dan muat kendaraan. Waktu oleh gerak keluar ialah waktu manuver kapal setelah menaikkan kendaraan dan penumpang ke kapal. Untuk mendapatkan waktu olah gerak kapal telah dilakukan pengamatan pada dermaga 1 . 
Tabel 3. Waktu Manuver kapal di Pelabuhan Bakauheni

\begin{tabular}{ccc}
\hline No & Jenis Kapal yang beroperasi & Waktu Manuver \\
\hline 1 & Suki & 30 \\
2 & BSP 1 & 26 \\
3 & Mustika Kencana & 30 \\
4 & HM Baruna & 26 \\
5 & Jatra 2 & 34 \\
6 & Shalem & 31 \\
& Total & 177 \\
& Rata-rata Manuver Kapal & 29,5 \\
\hline
\end{tabular}

Dari hasil pengamatan total waktu manuver kapal adalah 177 menit. Dengan menggunakan rumus didapat waktu manuver kapal sebagai berikut :

$\begin{array}{rll}\operatorname{Tm} & =\frac{\sum X}{N} & \text { (lihat persamaan 3) } \\ \operatorname{Tm} & =\frac{177}{6} \\ & =29,5 \text { menit }\end{array}$

Jadi waktu waktu olah gerak masuk dan oleh gerak keluar kapal adakah 29,5/2 = 14.75 menit. Dari data diatas dapat ditentukan headway dermaga. Headway dermaga adalah waktu minimum yang digunaakn kapal untuk menggunakan dermaga seperti bongkar muat dan manuver kapal pada saat dipelabuhan, sehingg headway dapat disebut sebagai waktu keberangkatan minimum. Untuk menghitung headway dapat digunakan persamaan dibawah ini :

$$
\mathrm{Hw}=\mathrm{tb}+\mathrm{tm}+\mathrm{Tm} \quad \text { (lihat persamaan } 6 \text { ) }
$$

Tabel 4. Headway Minimum setiap kapal di Dermaga I

\begin{tabular}{clcccc}
\hline No & $\begin{array}{l}\text { Jenis Kapal } \\
\text { yang beroperasi }\end{array}$ & $\begin{array}{c}\text { Waktu } \\
\text { Kenurunkan } \\
\text { ( menit) }\end{array}$ & $\begin{array}{c}\text { Waktu } \\
\text { Menaikkan } \\
\text { Kendaraan } \\
\text { (menit) }\end{array}$ & $\begin{array}{c}\text { Waktu } \\
\text { Manuver } \\
\text { (Menit) }\end{array}$ & $\begin{array}{c}\text { Headway } \\
\text { (Menit) }\end{array}$ \\
\hline 1 & Suki & 13,00 & 17,00 & 29,50 & 59,50 \\
2 & BSP 1 & 11,68 & 15,27 & 29,50 & 56,45 \\
3 & Mustika & 8,94 & 11,69 & 29,50 & 50,13 \\
4 & HM Baruna & 10,46 & 13,68 & 29,50 & 53,64 \\
5 & Jatra 2 & 7,11 & 9,30 & 29,50 & 45,91 \\
6 & Shalem & 6,70 & 8,77 & 29,50 & 44,97 \\
& Rata - Rata & 9,65 & 12,62 & 29,50 & 51,77 \\
\hline
\end{tabular}

Hasil analsiis data pelayanan kapal dibutuhkan waktu rata - rata untuk mengeluarkan kendaraan pada dermaga I sebesar 9,65 menit/kapal dan rata-rata memasukkan kendaraan sebesar 12,62 menit.kapal dan waktu manuver 29,50 menit.kapal.

Berdasarkan hasil analisis waktu bongkar muat dan manuver kapal di dermaga I maka nilai headway masing - masing kapal yang beroperasi didermaga I yaitu : Suki sebesar 59,50 menit, BSP I sebesar 56,45 menit; Mustika Kencana sebesar 50,13 menit, HM Baruna sebesar 53,64 menit, Jatra 2 sebesar 45,91 menit dan Shalem sebesar 44,97 menit. Rata - rata headway kapal didermaga I adalah 51,77 menit. Dengan kondisi seperti ini kapal - kapal yang beroperasi di Dermaga I memiliki kinerja yang baik karena waktu operasional di Dermaga I mendekati waktu optimal yang ditetapkan Pelabuhan Bakauheni. 


\section{Waktu Pelayanan Tiap Kapal}

Demaga I pelabuhan bakauheni memiliki 6 unit kapal yang beroperasi setiap harinya yang mempunyai kapasitas kapal yang berbeda dengan waktu berlayar 120 menit. Berdasarkan headway dan waktu tempuh kapal didermaga I didapatkan waktu siklus masing - masing kapal dalam 1 rit pelayaran bolak balok adalah; untuk kapal suki 6 jam/hari dengan jumlah sandar sebanyak 4 kali sandar.hari. Untuk lebih detail dapat dilihat pada tabel dibawah ini:

Tabel. Waktu Pelayanan tiap Kapal

\begin{tabular}{llccc}
\hline No & $\begin{array}{c}\text { Jenis Kapal } \\
\text { yang beroperasi }\end{array}$ & $\begin{array}{c}\text { Headway } \\
\text { Kapal } \\
\text { (Menit) }\end{array}$ & $\begin{array}{c}\text { Waktu } \\
\text { siklus } \\
\text { (Jam/hari) }\end{array}$ & $\begin{array}{c}\text { Jumlah } \\
\text { sandar }\end{array}$ \\
\hline 1 & Suki & 59,50 & 6,00 & 4 \\
2 & BSP 1 & 56,45 & 5,88 & 4 \\
& Mustika & 50,13 & 5,67 & 4 \\
3 & Kencana & 53,64 & 5,79 & 4 \\
4 & HM Baruna & 45,91 & 5,53 & 4 \\
5 & Jatra 2 & 44,97 & 5,50 & 4 \\
6 & Shalem & & & \\
\hline
\end{tabular}

Berdasarkan hasil perhitungan dapat dilihat bahwa headway kapal di Dermaga 1 sudah mendekati optimal dan sesuai dengan jadwal ditetapkan oleh pelabuhan yaitu sebesar 60 menit untuk operasional di dermaga I. Total 24 kali kapal bersandar di Dermaga I pada kondisi normal. Headway dan waktu berlabuh kapal dipengaruhi oleh waktu menurunkan dan menaikkan kendaraan.

\section{SIMPULAN}

Berdasarkan analisis data dapat disimpulkan bahwa nilai headway masing - masing kapal yang beroperasi didermaga I yaitu : Suki sebesar 59,50 menit, BSP I sebesar 56,45 menit; Mustika Kencana sebesar 50,13 menit, HM Baruna sebesar 53,64 menit, Jatra 2 sebesar 45,91 menit dan Shalem sebesar 44,97 menit. Rata - rata headway kapal didermaga I adalah 51,77 menit. Dari nilai tersebut menunjukkan bahwa operasional kapal pada Dermaga I di Pelabuhan Bakauheni sudah optimal karena kurang dari waktu yang telah ditetapkan oleh Pelabuhan Bakauhen dengan total 24 trip kapal di Dermaga I.

\section{REFERENSI/DAFTAR PUSTAKA}

Andriani, Irawati.2011. Optimalisasi Waktu Sandar Penyeberangan Untuk Meningkatkan Kinerja Pelayanan di Pelabuhan Merak-Bakauheni. Tesis. Program Pascasarjana Teknik Sipil Kekhususan Transportasi. Universitas Indonesia

Anonymus. 2014. Profil OPP Merak. Kementrian Perhubungan Direktorat Jendral Perhubungan Darat. Jakarta

Karyawan, I Dewa Made Alit. 2012. Analisis Waktu Baku Pelayanan Kapal di Pelabuhan Penyeberangan Lembar. Jurnal. Jurusan Teknik Sipil. Universitas Mataram.

Nasution, M.Nur, 2003 , Manajemen Transportasi. Ghalia Indonesia. Jakarta.

Solossa, Appi Yamsos. 2013. Perencanaan Pengembangan Pekabuhan Laut Sorong di Kota Sorong. Jurnal. Jurusan Teknik Sipil Universitas Sam Ratulangi. Makassar

Suparsa, I Gusti Putu. 2009. Optimasi Kinerja Pelabuhan Penyeberangan Ketapang - Gilimanuk. Jurnal. Teknik Sipil. Universitas Udayana. Denpasar.

Triatmodjo, Bambang. 1996. Perencanaan Pelabuhan. Beta Offset. Yogyakarta.

Tumangger, Ranto. 2013. Optimasi penyeberangan Bakauheni - Merak dengan rencana dibangunnya dermaga VI. Skripsi. Jurusan Teknik Sipil. Universitas Lampung. Bandar Lampung 